\title{
Combinatorial degradomics: Precision tools to unveil proteolytic processes in biological systems
}

\author{
Savickas, Simonas; Kastl, Philipp; auf dem Keller, Ulrich
}

Published in:

Biochimica et Biophysica Acta - Proteins and Proteomics

Link to article, DOI:

10.1016/j.bbapap.2020.140392

Publication date:

2020

Document Version

Peer reviewed version

Link back to DTU Orbit

Citation (APA):

Savickas, S., Kastl, P., \& auf dem Keller, U. (2020). Combinatorial degradomics: Precision tools to unveil proteolytic processes in biological systems. Biochimica et Biophysica Acta - Proteins and Proteomics, 1868(6), 140392]. https://doi.org/10.1016/j.bbapap.2020.140392

\section{General rights}

Copyright and moral rights for the publications made accessible in the public portal are retained by the authors and/or other copyright owners and it is a condition of accessing publications that users recognise and abide by the legal requirements associated with these rights.

- Users may download and print one copy of any publication from the public portal for the purpose of private study or research.

- You may not further distribute the material or use it for any profit-making activity or commercial gain

- You may freely distribute the URL identifying the publication in the public portal 


\section{Journal Pre-proof}

Combinatorial degradomics: Precision tools to unveil proteolytic processes in biological systems



Simonas Savickas, Philipp Kastl, Ulrich auf dem Keller

PII: $\quad$ S1570-9639(20)30033-9

DOI: $\quad$ https://doi.org/10.1016/j.bbapap.2020.140392

Reference: $\quad$ BBAPAP 140392

To appear in: $\quad B B A-$ Proteins and Proteomics

Received date: $\quad 22$ November 2019

Revised date: $\quad 13$ February 2020

Accepted date: $\quad 14$ February 2020

Please cite this article as: S. Savickas, P. Kastl and U.a.d. Keller, Combinatorial degradomics: Precision tools to unveil proteolytic processes in biological systems, $B B A$ Proteins and Proteomics(2020), https://doi.org/10.1016/j.bbapap.2020.140392

This is a PDF file of an article that has undergone enhancements after acceptance, such as the addition of a cover page and metadata, and formatting for readability, but it is not yet the definitive version of record. This version will undergo additional copyediting, typesetting and review before it is published in its final form, but we are providing this version to give early visibility of the article. Please note that, during the production process, errors may be discovered which could affect the content, and all legal disclaimers that apply to the journal pertain.

(C) 2020 Published by Elsevier. 
Combinatorial degradomics: precision tools to unveil proteolytic processes in

\title{
biological systems
}

\author{
Simonas Savickas ${ }^{*}$, Philipp Kastl ${ }^{*}$, and Ulrich auf dem Keller ${ }^{\#}$ \\ Department of Biotechnology and Biomedicine, Technical University of Denmark, \\ DK-2800 Kongens Lyngby, Denmark
}

\section{\#Address for correspondence:}

Prof. Ulrich auf dem Keller

Technical University of Denmark

Department of Biotechnology and Bioengineering

Søltofts Plads, Building 224, Room 114

DK-2800 Kongens Lyngby

Denmark

e-mail: uadk@dtu.dk

Tel.: $\quad$ +45 45252791

*These authors contributed equally to th.- work.

Running title: Protease degrac'nni:s 


\begin{abstract}
The biological activity of a protein is regulated at many levels ranging from control of transcription and translation to post-translational modifications (PTM). Proteolytic processing is an irreversible PTM generating novel isoforms of a mature protein termed proteoforms. Proteoform dynamics is a major focus of current proteome research, since it has been associated with many pathological conditions. Mass-spectrometry (MS)-based proteomics and PTM-specific enrichment workflows have become the methods of choice to study proteoforms in vitro and in vivo. Here, we give an overview of currently ava.. 7 ble MS-based degradomics methods and outline how they can be optimally applied to stu ' $v$ pr stease cleavage events. We discuss the advantages and disadvantages of selected appr ach $: s$ and describe state-of-the-art improvements in degradomics technologies. By intru'king the concept of combinatorial degradomics, a combination of global discovery dešra romics and highly sensitive targeted degradomics, we demonstrate how MS-based dı g aiomics further evolves as a powerful tool in biomedical protease research.
\end{abstract}

Keywords: protease, mass spectromet' $y$, proteomics, degradomics, targeted degradomics, combinatorial degradomics 


\section{Introduction}

Over the past decades, the dogma of molecular biology has dramatically evolved from the simple concept of single gene-transcript-protein relations. It is now clear that one gene can encode many transcriptional products, which are translated into even more amino acid chains making up proteins with multiple biological activities under different conditions. Thus, to understand the function of a protein in a specific biological setting it is important to elucidate its identity, abundance and how generation of different proteoforms is dynamically regulated during its lifetime [1,2]. At the transcriptional level, proteoform dynamics is mediated by transcription factors and alternative splicing, leading to generation of protein isoforms, while at the protein level genc ation of new proteoforms is conferred by post-translational modifications (PTMs). In recent year th a analysis of regulation at the protein level has become a major focus, which resulted in estak!i $h m \in \mathrm{nt}$ of large initiatives, such as the Human Proteome Organization (HUPO, www.hupo.org) and .w गS sciated human protein project (HPP). Regulation of protein activity at the protein level is dynamir, :-pends on the physiological context and ultimately determines the terminal function of a pr itf, $r$ This knowledge could therefore be used to identify potential novel disease markers and al' _ " $\iota$ rthe development of specialized the rapeutics that target only one specific proteoform [3].

State-of-the-art system-wide analytical motı, nds like mass spectrometry (MS)-based proteomics have become the preferred approaches to - nal 17 - protein functions in vitro and in vivo. Although proteomics is based on the simple physical cor opt that by applying an electric field in a high vacuum charged peptides and/or proteins can be separated and identified by their masses, it has become a highly specialized and complex ficit ur research. As an example, MS is used to study different protein proteoforms resulting t $: m ; r M s$, like phosphorylation, ubiquitination or acetylation [4]. Limited proteolysis of substrates is a very important but often neglected irreversible PTM, which terminally alters protein fate and creates novel proteoforms. Substrates undergoing proteolysis by proteases are often signaling proteins like cytokines, chemokines, other proteases or extracellular matrix components. Those molecules are all involved in regulating development, immune and inflammatory responses, as well as many pathological conditions ranging from cardiovascular to chronic inflammatory diseases or cancer. In order to better understand those processes and identify new biomarkers for the diagnosis of their associated diseases, substrate proteolysis is now the focus of many research groups around the globe. Based on the interest in proteolysis the field of degradomics has been established, aiming at analyzing proteolysis both at the substrate and the protease level by MS-based methods. Over the past 
years, multiple specialized degradomics methods have been developed and it is getting more and more challenging to keep an overview of these approaches and to understand how they can be optimally applied to study a specific problem. In the following, we will provide an overview of major degradomics approaches, how currently available MS-based methods can be used in protease research and discuss the future potential of the field.

\section{Proteomics and degradomics}

As a first step to characterize a proteome and its dynamics, usually a whole proteome analysis of a biological sample of interest is conducted, termed discovery-ba ed proteomics. Most common discovery-based proteomics analyses follow the same, classic bottc .n-: 0 -proteomics workflow. After isolating the proteome from a biological sample, proteins are digf « $\gamma_{\Perp} \ldots$ to peptides using a site-specific endopeptidase (e.g. Trypsin, LysC, ArgC, Lysarginase or GluC). $\Gamma$ ' ptlues are then fractionated by reversephase chromatography, positively ionized, and analyzed $n$th mass spectrometer according to their mass to charge $(\mathrm{m} / \mathrm{z})$ value. The detected peptides and heir abundances can then be related to the original protein by a database search against the wr $\boldsymbol{\jmath}^{-} \mathrm{pr}$, teome sequence of the target organism. The constant development of new, highly sensitiv ,, hi ,h-r, solution mass spectrometers in conjunction with optimized chemical labeling reagents to analyze, uultiple samples in a single experiment (multiplexing) allows for unprecedented peptide identifiratı $\backslash n$ and quantification sensitivity below femtomolar ranges. Indeed, as whole proteome analysis $\mathrm{c}^{\mathrm{f}} \mathrm{hic}$ ' $\mathrm{s}$ jical samples showed, the abundance of proteins can span a range of more than ten orders of $n$ ag. itude $[5,6]$. This is a major problem, because due to the principles of MS analysis peptides derive' trom high abundance proteins have the tendency to mask low abundance peptides deri,ei' lium low abundance proteins (Fig. 2A). Moreover, proteolytically generated proteoforms $a_{1} \gamma_{\text {L }}$ ir peptides are even less abundant, since substrate proteolysis is often incomplete. This can pote, , clally be overcome by prior depletion of high-abundance proteins (e.g. using combinatorial peptide ligand libraries (CPLLs) [7]), as well as affinity purification (e.g. upon biotinylation [8]) and additional sample fractionation (e.g. by UHPLC or affinity chromatography). In the case of in vitro experiments, this might be a feasible approach, since access to sample is usually not a problem, but amounts of in vivo material is limited and any additional purification step increases the risk of loss of proteins and in particular the lowly abundant proteoforms. In order to solve this challenge and allow for the nearly exclusive identification of protease-generated peptides, specialized positional proteomics methods have been invented. These methods combine multiplexing of samples by isotopiclabeling with a specific peptide enrichment step during sample preparation, depleting the sample of internal tryptic 
endopeptidase-generated peptides and enriching for only natural as well as protease-generated $\mathrm{N}$ terminal peptides. Over the past years multiple different positional degradomics methods have been presented, with some being project-oriented and rarely been used besides for their original studies. Others have become established discovery degradomics methods used to identify a multitude of protease cleavage events (Fig. 1). Here, we willfocus on the two majorly applied methods in detail, but also give a brief overview of some more specialized alternatives.



Figure 1: Number of published studies using necitıed degradomics techniques according to PubMed searches. Data collected in November 2019.

\section{Discovery degrain $n_{1}: \sim$, as tool to identify protease substrates}

The first method developed for specific enrichment of protein $\mathrm{N}$-termini from whole proteomes was combined fractional diagonal chromatography (COFRADIC) [9]. In COFRADIC, proteins are reduced and alkylated to block cysteine side chains followed by trideutero-acetylation of primary N-termini (natural and protease-generated) (Fig. 2B, right panel). Afterwards, proteins are trypsin digested, resulting in two species of $\mathrm{N}$-terminal peptides: (i) acetylated original peptides and (ii) tryptic peptides with free $\alpha$ amines. After the tryptic digest, samples are purified by two orthogonal reverse-phase high performance liquid chromatography (HPLC) steps. The first HPLC step fractionates the sample and reduces its complexity, whereas prior to the second step the C-terminal and tryptic peptides are hydrophobically labeled with 2,4,6-trinitrobenzenesulfonic acid (TNBS). Primary N-termini are then isolated from the 
sample due to their altered retention time on the column. A drawback of COFRADIC are limited multiplexing capabilities due to the acetylation of free $\mathrm{N}$-termini and restriction of sample labeling to stable isotope labeling with amino acids in cell culture (SILAC), since other commercial chemical labeling reagents bind to the primary amines of a peptide. A modified version of COFRADIC termed charge-based fractional diagonal chromatography (ChaFRADIC) was developed, which improves its efficiency by employing strong cation exchange chromatography (SCX) prior to the orthogonal HPLC step [10]. This allows for multiplex label ing of native and protease-generated $\mathrm{N}$-termini with amine-reactive chemical reagents, instead of blocking by acetylation. ChaFRADIC has recently been miniaturized, so that the separation can be performed on a self-made column in a pipet tip, redı ing sample input to below five $\mu \mathrm{g}$ and making the workflow less dependable on a core facility witt exp ?nsive, reliable HPLC systems [11]. 


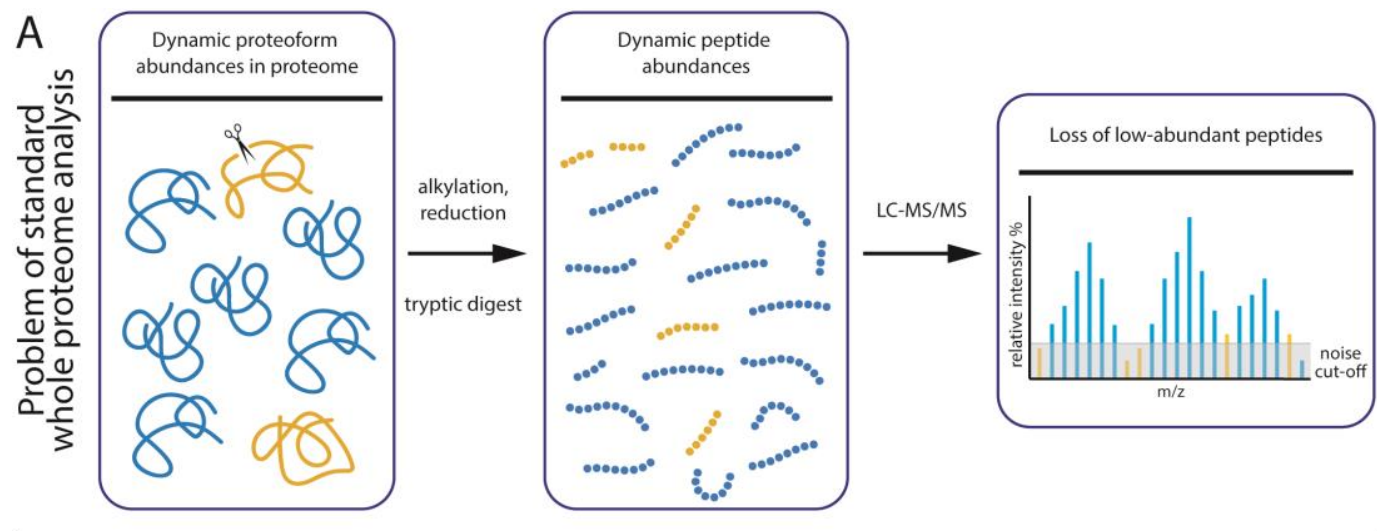

B
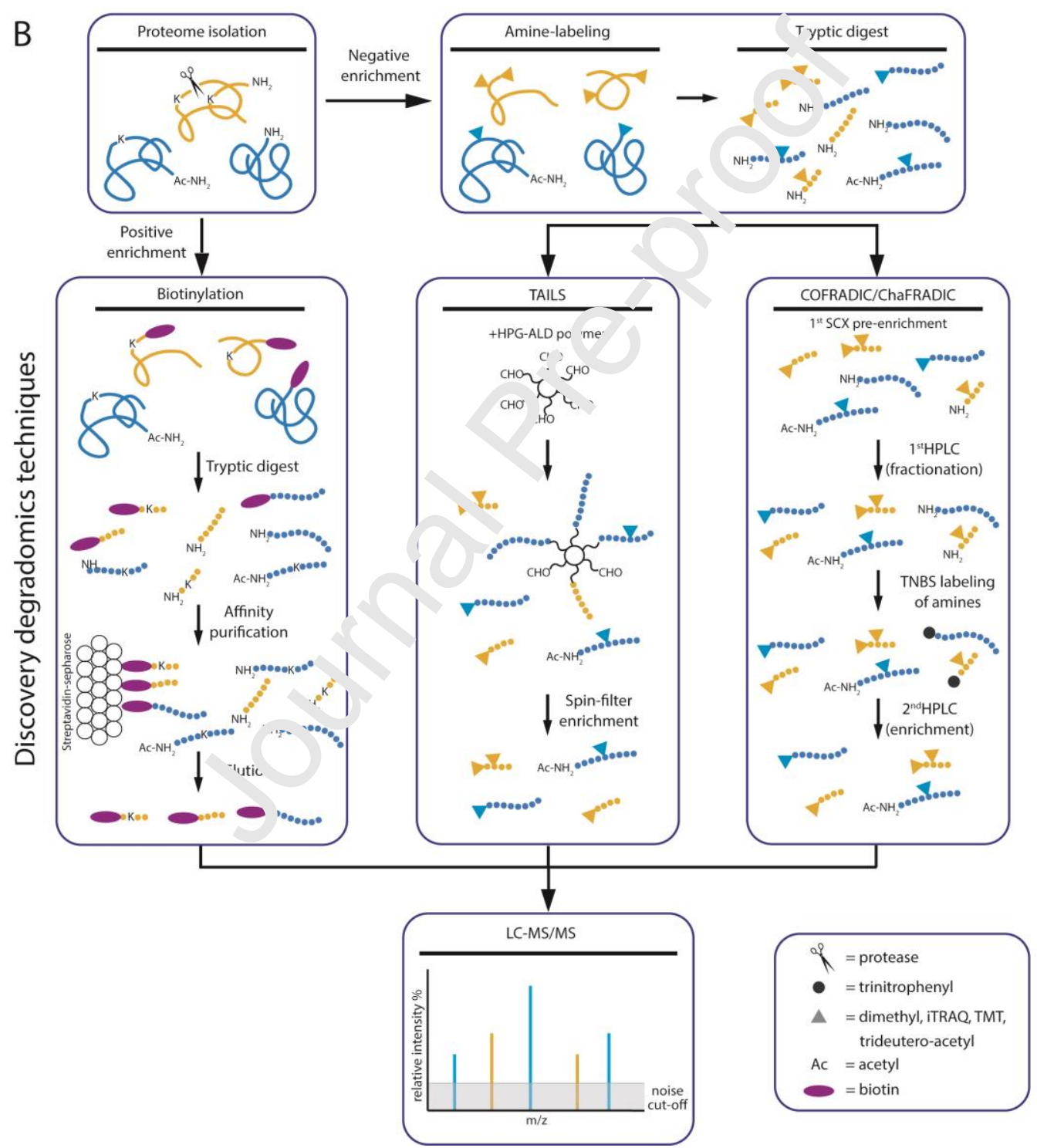

Figure 2: Discovery degradomics allow for identification of low abundance proteoforms in biological samples. (A) Tra ditional whole proteome s hotgun proteomics fails to detect many low a bundance proteins due to low signal-to-noise ratios. (B) Pe ptide enrichment methods in discovery degradomics a llow for detection of low abundance protease-generated peptides in complex biologicals smples. Identification of $\mathrm{N}$-terminal peptides ca $\mathrm{n}$ be improved by either positive (left panel) or negative (middle and right panel) enrichment strategies. 
Another powerful positional proteomics method widely applied is terminal amine isotopic labeling of substrates (TAILS) ([12]; for a recent protocol see [13]). Like COFRADIC and ChaFRADIC, TAILS is based on negative enrichment of protein $\mathrm{N}$-termini and protease-generated neo- $\mathrm{N}$-terminal peptides (Fig. 2B, middle panel). Here, an isotopiclabel introduced by whole protein labeling chemically blocks all primary $\alpha$ - and $\varepsilon$-amines. After the tryptic digest, tryptic peptides are removed from the sample by binding to an amine-reactive highly-branched polyglycerol aldehyde polymer (HPG-ALD polymer) via their unblocked primary $\mathrm{N}$-terminal $\alpha$-amines. Since chemically or natively blocked (e.g. acetylated) $\mathrm{N}$-terminal peptides cannot bind to this polymer, they can be collected in the flow-through of size-exclusion spin-columns. Similar to ChaFRADIC, TAILS allows for multiplexing of samples by isotc, ic labeling at the protein level prior to the tryptic digest. However, for TAILS this can be extend ! $\mathrm{u} u$ to 16-plex by use of aminereactive tandem mass tags (TMT). Since less chromatography ste is ar involved, there is a lower risk of peptide losses during sample preparation, but the polyme, null-out depends on prior $\mathrm{N}$-terminal blocking and efficiency of proteome labeling [14]. Multip oxir g provides an additional benefit, since increasing the number of samples analyzed within $\operatorname{sir}_{0}^{-1} 0$ TMT-vased TAILS experiment results in more total protein, which on the other hand allows tn rec....e the amount of total protein needed from individual samples.

An alternative to COFRADIC, ChaFRADIC $-r$ TAILS is based on removing internal tryptic peptides via phospho-tagging (PTAG) followed by tit. $\mathrm{n}$; ur . dioxide $\left(\mathrm{TiO}_{2}\right)$ affinity chromatography [15]. Additionally, natural und protease-generated $\mathrm{N}-+\cdot \mathrm{rm}$ ı.. can be positively enriched by $\underline{\mathrm{N}}$-terminalomics by $\underline{\text { Chemical }}$ Labeling of the $\alpha$ - $\underline{\text { Amine of }}$ Prcte. 's (N-CLAP) [16] or subtiligase enzymatic labeling [8], which both specifically chemically label u arines allowing for their affinity purification (Fig. 2B, left panel). Secretome Protein $\underline{E} n_{1} \cdot h_{1}$ 'en with $\underline{\text { Click }}$ Sugars (SPECS) metabolically labels glycosylated proteins, followed by click chemistr /-mediated biotinylation for avidin affinity enrichment and enables in particular identification of protease-mediated surface shedding events but without providing information on protease cleavage sites [17] [18].

Even though identifying the $\mathrm{N}$-terminal peptide of a cleaved substrate is often sufficient for protease substrate discovery, C-terminal cleavage products are of as much interest. However, enrichment of Cterminal peptides is not as commonly used, since carboxyl groups are less reactive than primary amines. Nevertheless, TAILS and COFRADIC have been adjusted to allow for enrichment of natural and proteasegenerated protein C-termini. For TAILS, additionally to $\mathrm{N}$-terminal blocking, ethanolamine is coupled to the C-terminus of peptides allowing for the negative enrichment of protein C-termini using a high- 
molecular-weight poly-allylamine polymer [19]. C-terminal COFRADIC employs an extra labeling step of primary amines of C-terminal peptides, followed by an additional round of HPLC fractionation [20].

Positive and negative enrichment methods both come with their own advantages and disadvantages and are thus suitable to address different biological questions. Negative enrichment methods allow for in-depth analysis of both the proteome (before enrichment) and the degradome (after enrichment) with the possibility to multiplex experiments by chemical labeling of $\alpha$-and $\varepsilon$-amines, which increases quantification and identification confid ence between multiple samples. Importantly, they also enrich for naturally modified N-/C-terminal peptides (e.g. acetylated N-termini), since those will not bind to the matrix used for negative enrichment. While using readily available che micals for labeling, negative enrichment methods require either extensive fractionation (COF, $A D^{\prime}=$, ChaFRADIC) or specialized polymers (TAILS) for depletion of internal tryptic peptides, whirh, hov ever, are now publicly available. As a major technical challenge, positive en richment of $\mathrm{N}$-ter $\ldots$... רa , septides requires selectivelabeling of $\mathrm{N}$-terminal $\alpha$-amines. This precludes identification of naturalı, olocked protein $\mathrm{N}$-termini but might be advantageous for identification of protease cleavage $v r . n$ s in cytoplasmic samples with high numbers


mostly restricted to SILAC or label-free quantı - - ttion, since isotopic labels would have to be introduced with $\mathrm{N}$-terminal affinity tags. An exceptı $n$ is subtiligase enzymatic labeling, which allows isotopic labeling of $\varepsilon$-amines after positive enric $/ r_{e}$ : but is restricted to multiplexed quantification of lysine containing $\mathrm{N}$-terminal peptides and requires access to the subtiligase enzyme.

Since their first publication discu 'ery degradomics methods have been extensively used to identify proteases and their specif' ¿ 'avage products in various biological backgrounds and from all kinds of different species ranging : "Oı E. Coli [9,21], Arabidopsis thaliana [10], model animals like rodents [22] and pigs [23] to humans [ $\angle+]$. At time of writing, a simple PubMed search with the keywords "Terminal Amine Isotopic Labeling of Substrates" or "COFRADIC" resulted in 49 (for TAILS) and 42 (for COFRADIC) research articles, respectively (Fig. 1). Additional manual curation revealed that those search terms did not even provide a full list of all articles published using these methods. Since discussing all studies that employed a discovery degradomics technique would be beyond the scope of this review, we provide a compilation of research articles published up till November 2019 and based on PubMed searches for the associated method names (Table 1). Reference numbers in this table refer to PubMed accession numbers of corresponding publications listed in Table S1. 
Table 1: Compilation of published discovery degradomics methods. Ref. \# refers to numbers in Table S1.

\begin{tabular}{|c|c|c|c|c|c|}
\hline$\#$ & Technique & $\begin{array}{l}\text { Preparation } \\
\text { time }\end{array}$ & Organism & Sample type & Ref. \# \\
\hline 49 & TAILS & $48 \mathrm{~h}$ & \multicolumn{2}{|c|}{$\begin{array}{l}\text { Popular technique: from recombinant proteins to clinical } \\
\text { patient testing }\end{array}$} & $1-49$ \\
\hline 42 & COFRADIC & $48 h$ & \multicolumn{2}{|c|}{$\begin{array}{l}\text { Popular technique: from recombinant proteins to clinical } \\
\text { patient testing }\end{array}$} & $50-91$ \\
\hline \multirow[t]{3}{*}{1} & \multirow[t]{3}{*}{ HUNTER } & \multirow[t]{3}{*}{$48 \mathrm{~h}$} & Rat & Brain & 135 \\
\hline & & & Plant & Arabidopsis thaliana & 135 \\
\hline & & & Human & $\begin{array}{l}\text { HeLa, B-ALL, 697, blood plasma, } \\
\text { primary B-ALL, primary AML, B-cells, } \\
\text { monocytes, natural killer cells, NKT }\end{array}$ & 135 \\
\hline \multirow[t]{2}{*}{2} & \multirow[t]{2}{*}{ CheFRADIC } & \multirow[t]{2}{*}{$48 \mathrm{~h}$} & Plant & Arabidopsis thaliana & 136 \\
\hline & & & Human & Platelets & 137 \\
\hline \multirow[t]{4}{*}{7} & \multirow{4}{*}{$\begin{array}{l}\text { Enzymatic } \\
\text { Biotinylation }\end{array}$} & \multirow[t]{4}{*}{$60 \mathrm{~h}$} & Bacteria & Escherichia coli & $123,125,126$ \\
\hline & & & Yeast & Saccharomyces c'ic. 'siue & 123 \\
\hline & & & $\begin{array}{l}\text { Recombinant } \\
\text { Protein }\end{array}$ & Aprotinin & 123,126 \\
\hline & & & Human & $\begin{array}{l}\text { HEK-293A, ser } \mathrm{m} \text {, Jurkat cells, blood } \\
\text { plasma }\end{array}$ & $\begin{array}{l}123,124,126, \\
127\end{array}$ \\
\hline \multirow[t]{3}{*}{6} & \multirow{3}{*}{$\begin{array}{l}\text { Yeast-two- } \\
\text { Hybrid in } \\
\text { Proteolysis }\end{array}$} & & Human & $\begin{array}{l}\text { HEK293T, HCT } \perp 6, \text { Daudi, THP-1, OCl- } \\
\text { AM 2, dt idritic cells, }\end{array}$ & $129-132$ \\
\hline & & & $\begin{array}{l}\text { Recombinant } \\
\text { protein }\end{array}$ & $F \cdot \bar{X}$ AIv, Fibrinogen & 129,133 \\
\hline & & & Mouse & Megakaryocytes, platelets & 134 \\
\hline \multirow[t]{2}{*}{4} & \multirow[t]{2}{*}{ SPECS } & \multirow[t]{2}{*}{$96 \mathrm{~h}$} & Mouse & $\begin{array}{l}\text {-ortical neurons (secretome), MEF } \\
\text { (secretome), primary neurons } \\
\text { (secretome) }\end{array}$ & $92,94,95$ \\
\hline & & & Hum $=n$ & HEK293T (secretome) & 93,94 \\
\hline 9 & PROTOMAP & $24 \mathrm{~h}$ & $\mathrm{Hu} \overline{\mathrm{an}}-$ & $\begin{array}{l}\text { Blood, Jurkat T Cells, erythrocytes, } \\
\text { MHCC97L, HCCLM6, A549, PC-3 }\end{array}$ & $97-104$ \\
\hline \multirow[t]{2}{*}{6} & \multirow[t]{2}{*}{$\begin{array}{l}\text { TMPP, N-TOP, } \\
\text { dN-TOP }\end{array}$} & \multirow[t]{2}{*}{$24 \mathrm{~h}$} & $\begin{array}{l}\text { Pecu mbinant } \\
\text { pr stein }\end{array}$ & Recombinant glycoproteins, Hz6F4-2 & $\begin{array}{l}105,106,107, \\
110\end{array}$ \\
\hline & & & Bacterium & $\begin{array}{l}\text { Myobacterium smegmatis, } \\
\text { Herminiimonas arsenicoxydans }\end{array}$ & 108,109 \\
\hline 1 & NEDDylator & & Human & Jurkat & 128 \\
\hline \multirow[t]{2}{*}{4} & \multirow[t]{2}{*}{ ATOMS } & \multirow[t]{2}{*}{$48 \mathrm{~h}$} & Human & $\begin{array}{l}\text { Primary macrophages, BJ cells, HUVEC, } \\
\text { skin }\end{array}$ & 111,112 \\
\hline & & & $\begin{array}{l}\text { Recombinant } \\
\text { protein }\end{array}$ & Fibronectin-1, LM-111 & 113 \\
\hline \multirow[t]{3}{*}{10} & \multirow[t]{3}{*}{$\begin{array}{l}\text { C- } \\
\text { Terminomics }\end{array}$} & \multirow[t]{3}{*}{$48 \mathrm{~h}$} & $\begin{array}{l}\text { Recombinant } \\
\text { protein }\end{array}$ & Bovine serum albumin, $\beta$-casein & 114 \\
\hline & & & Human & $293 T$ & 115 \\
\hline & & & Bacteria/Yeast & $\begin{array}{l}\text { Saccharomyces cerevisiae, Escherichia } \\
\text { coli, Thermoanaerobacter } \\
\text { tengcongensis }\end{array}$ & $116-121$ \\
\hline 1 & PTAG & & Bacteria/Yeast & $\begin{array}{l}\text { Neisseria meningitides, Saccharomyces } \\
\text { cerevisiae }\end{array}$ & 122 \\
\hline
\end{tabular}




\section{Targeted degradomics to validate and extend results from discovery degradomics approaches}

Discovery proteomics and degradomics approaches are inherently challenged by the complexity of the sample proteome. Only applying differential depletion steps or immunoprecipitation methods using specific antibodies might enable identification and quantification of specific low abundance proteins and protease cleavage events. Moreover, inherent undersampling in shotgun proteomics can prevent comprehensive positional peptide mapping of identified substrate proteins. Thus, it might not be clear, if a unique proteoform was generated by limited proteolysis or if it resulted from rather unspecific degradation of the mature protein. By harnessing the sensitivity, precision and ability to overcome interference of the whole proteome, targeted degradomics ensures $t_{1}$, ?t proteoforms and cleavage events of interest can be analyzed with high sensitivity and com, ret ansive coverage of substrate proteins.

The vast amount of information accessible today providn; an ole resources to identify a proteoform cleavage as well as a candidate protease of interest. Dal obtained by discovery degradomics approaches is stored in databases like $M^{r}: K^{-P S}$ (https://www.ebi.ac.uk/merops/), CutDB (https://omictools.com/cutdb-tool), TopF $\mathrm{NL}$ i.http://clipserve.clip.ubc.ca/topfind), CaspDB (https://omictools.com/caspdb-tool), Degrabast 'https://wellslab.ucsf.edu/degrabase/) and others [2529]. Those databases may also contain mu, iple isoforms of a cleaved proteoform associated with different biological contexts $[29,30]$. A $d \mathrm{di}$ ir nally, extracted datasets allow for prediction of candidate proteases based on known substra ce ¿'eavage motif preferences of endopeptidases. Validation of direct protease-substrate relations rev $7 / \in d$ by discovery degradomics require experimental evidence that identified proteoforms ar _ i. aced the result of a "true" cleavage event performed by a specific protease. This validatio. Can be achieved by a targeted degradomics experiment. In contrast to discovery degradomics, cargeted degradomics aims at monitoring specific proteoforms and their cleavage products rather than measuring as many events as possible. As an example, a substrate of interest is co-incubated with a candidate protease and the mass spectrometer set to specifically scan either the original or the proteolytically generated peptide. Thereby, both proteoforms can be identified and their relative abundances determined [31]. As long as the peptide target is known, targeted degradomics allows identifying the same target peptide e.g. in a simple cell-free protein system, in cell culture and in in vivo systems [32]. For instance, targeted proteomics was successfully applied to compare the same peptide target across different cancer cell lines, ranging from pancreatic cancer to colorectal adenosarcoma, breast cancer, and metastatic adenosarcoma [33]. Similarly, it is possible to 
monitor the same cleaved peptide in human plasma, urine, liver, kidney, heart, skin, etc. Furthermore, targeted proteomics and degradomics is specifically suited for cross-tissue and cross-laboratory studies and basically only limited by robustness of chromatography and instrument availability [34,35].

In general, trypsin is used as a standard working protease for bottom-up proteomics and degradomics, but with the emergence of alternative endopeptidases, such as LysC, AspN, GluC, Pepsin, and LysargiNase the coverage of the full proteome as well as the $\mathrm{N}$-terminome has significantly increased $[31,36]$. Like in discovery approaches, different endopeptidases can be applied to targeted proteomics and degradomics to cover the naturally occurring proteome and degradome with maximum depth. Therefore, using the appropriate endopeptidase it is now possible to a velop targeted degradomics assays for most protease cleavage events. As long as the peptide of ir. 'erf st has a length between 6 and 26 amino acids, the mass-spectrometer will identify the fragm $\sim r^{2} `[3 \mathrm{f}]$. Still, due to a limited variety of endopeptidases identification of specific fragments might $b_{-}{ }^{n}{ }^{0}$. ibited. As an alternative, a top-down proteomics approach might be applied, in which the intact. $u_{1}$. igested proteome is directly injected into the LC-MS system. However, top-down-proteomics ar.e other challenges, such as limited solubility, insignificant ionization and complex fragmen+_-'o, of proteins [37].

Through PTM crosstalk other PTMs of the paren, , rotein can affect generation of proteolyticfragments. Using targeted degradomics, PTMs such ar pr, `sphorylation, glycosylation and ubiquitination that may interfere with proteolytic cleavage ca s se concomitantly monitored, often without additional enrichment steps [13]. Monitorin; $t_{1}$. target peptide with and without a modification only requires correction of the target mass anc de iermination of respective elution times. Concomitant analysis of multiple PTMs in an endo', r. vus biological environment allows for a more in-depth analysis of the sample and provides ada. ${ }^{i}{ }^{\prime}$ ı al insight into complex biological systems [38,39].

In addition to validating peptide cleavage events, targeted degradomics data can be quantitatively analyzed with high accuracy, e.g. to proportionally assess cleaved and non-cleaved proteoforms. This can be achieved by measuring (i) the intensity of the ion chromatographic peak, (ii) counting peptide spectrum matches or (iii) comparing absolute peptide concentration to the synthetic reference spectrum [40]. The most common quantification technique determines the area under the curve of each transition recorded at the peptide fragment level [41,42], which is a flexible and convenient method to select the right values for the identified peptide. These values can then be analyzed using standard data processing software, such as Microsoft Excel, GraphPad Prism, SPSS, or statistical programming 
languages like R, Matlab or Python $[43,44]$. All of these provide convenient packages for targeted degradomics data analysis and statistical methods to assist in data interpretation.

Targeted degradomics is becoming more and more popular as a technique to verify and reliably quantify a cleavage event of choice [31]. This is supported by the advances in sensitivity, precision, speed, and robustness of mass spectrometers that have reached and in some cases already surpassed traditional antibody-based methods [45]. The lack of reliable antibodies, the inability to raise an antibody to a specific cleavage product, or the time it takes to produce an antibody for a specific target protein is a limitation that might be overcome by mass spectrometry-based targeted degradomics.

With better access, affordable prices and availability of proteomics un facilities, mass spectrometrybased proteomics is readily becoming available to a wider -u. nıunity of protease researchers. Initiatives like the Clinical Proteomics Tumc mnalysis Consortium (CPTAC, https://www.hupo.org/Clinical-Proteome-Tumor-Analys'-Cor sortium-(CPTAC)) and the European Proteomics Infrastructure Consortium providing access ; ¿PIC-:S, https://epic-xs.eu/) now also offer degradomics technologies and have opened up rna $v$ carvices to biomedical scientists and clinical researchers.

\section{Future perspective for combinatc vial degradomics technologies}

If combined in an approach we term c sm vinatorial degradomics (Fig. 3), discovery and targeted degradomics become a powerful tnc 'to icientify, validate and characterize proteolytic events in every type of biological sample. 


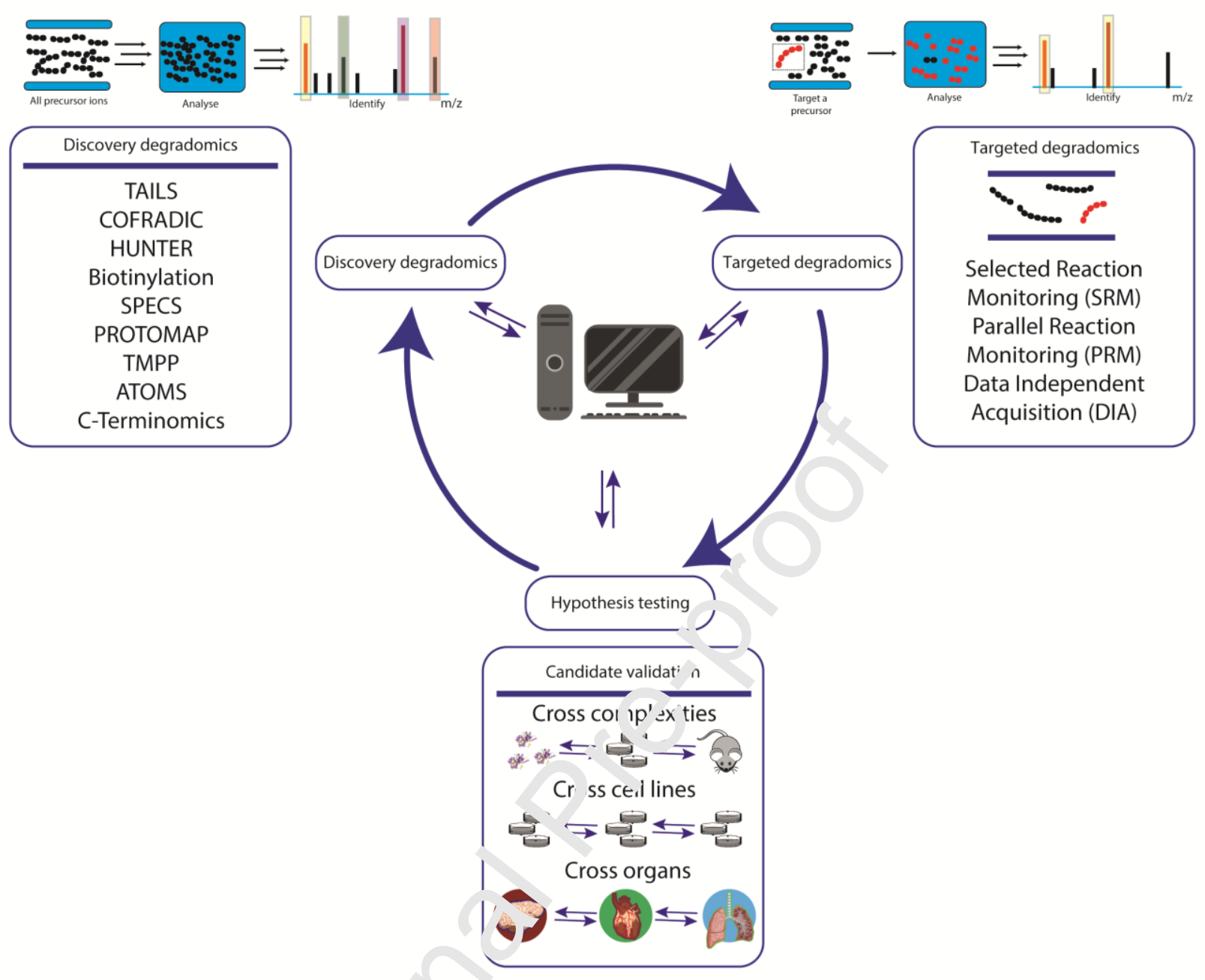

Figure 3: Overview of combinatorial degra 'omics. Combination of discovery and targeted degradomics methods allows monitoring of protease cleavage events I, all kinds of biological samples. Ca ndidate cleavages identified from combinatorial degra domics have to be ultimately ve. fied by in vitro/in vivo testing across different systems. All three approaches integrate with database profiling and $n \leq x t-\varepsilon$ ? neration machine learning algorithms.

Combinatorial degradomics has al ready been applied to better understand known and to decipher novel protease signaling pathways. Uncovering new modes of complement activation, providing unprecedented insight into inflammation and cancer signaling and unraveling specificity profiles for entire protease families are only a few examples of how degradomics technologies have revolutionized protease research towards a comprehensive understanding of the protease web [46-49]. Although data recorded in system-wide analyses is compiled in data repositories, designing experiments or software algorithms to orthogonally but comprehensively validate the insights gained by degradomics experiments is still a major challenge. Furthermore, more streamlined techniques are needed to confirm biological relevance of phenomena observed in such hypothesis-generating studies. 
One of the techniques, which has been applied to discovery degradomics is data independent acquisition (DIA) mass spectrometry, allowing discovery and quantification of thousands of peptides and newly generated proteoforms [50,51]. DIA shifts the paradigm of identifying the most abundant ions in a peptide mixture to measuring specified windows of masses and thus turns the stoch astic nature of data dependent acquisition (DDA) shotgun proteomics into a more unbiased approach [52]. Given the fundamental differences in modes of data acquisition, DIA can also serve as orthogonal technology for high-throughput validation of DDA data. In general, DIA relies on extensive spectral libraries that need to be recorded in separate DDA measurements, significantly increasing mass s pectrometry time. However, use of pre-generated libraries can now be completely avoided, e.g. byc. nbining DIA with Prosit, a deep learning algorithm for peptide tandem mass spectra prediction [53.'

Quantitative discovery degradomics has highly benefitted from ?, tenr ed multiplexing capabilities, now allowing concomitant analysis of up to sixteen samples wi+... he newly released 16 plex Tandem Mass Tag (TMT) reagents. By combining sixteen samples into a s1. . - le injection, the pos sibility to identify a target cleavage can be increased, the time taken $f r$. nass spectrometry analysis reduced and a significantly higher sample throughput achie... Tependent on the chemistry of isobaric labeling reagents, even higher levels of multiplexiric an be realized [54], which are expected to soon be commercially available for proteomics anc i tegradomics applications.

Together with the development of no'el imine-reactive labeling reagents, extensive off-line peptide fractionation has the potential ts s. Tnificantly increase throughput and $\mathrm{N}$-terminome coverage in discovery degradomics. By establ, - hir,g automated set-ups using reverse phase high pH chromatography a sample can be fractionat $-u$ in $n$ more than 48 fractions, dramatically increasing the coverage of the proteome [51,55]. Inject, ' $\sigma$ each fraction independently using a classical DDA mode for analysis and combining all fractions in $\iota$ a single output file, it is possible to identify over $10.000 \mathrm{~N}$-terminal peptides from a single sample. This includes multiple proteoforms that were previously undiscovered or required complex steps of targeted precipitation [45]. Combining fractionation and DIA, the groups of Huesgen and Lange have taken another approach to N-terminal enrichment. Instead of using the HPG-ALD polymer regularly applied in TAILS, they modified the HYTANE method for negative enrichment of Ntermini [56]. With this approach, they have managed to identify more than $8000 \mathrm{~N}$-termini out of 1 Million HeLa cells starting material [51].

High-throughput validation of discovery degradomics results does not only depend on the sensitivity and throughput of the validation methods, but also on data processing strategies. As an example, Triggered 


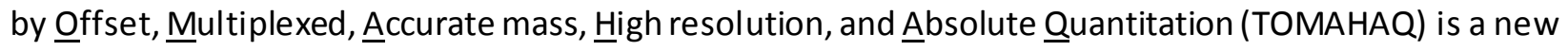
software tool for targeted proteomics that combines TMT-based multiplexing with targeted analyses. In conjunction with the new TMT 16plex kit, TMTO and TMT super heavy, TOMAHAQ and TOMAHAQ companion allow rapid and reliable target quantification of thousands of targets at a time. Compared to regular targeted proteomics workflows this is a major boost in throughput and may also be used for validation of proteolytic cleavage events identified in discovery degradomics experiments [57-59].

Furthermore, by combining already existing techniques like TAILS and TOMAHAQ it will be possible to use $\mathrm{N}$-terminally enriched fractions as template libraries to monitnr and quantify the $\mathrm{N}$-termini of samples without enrichment. This technique will reduce sample loss due li long enrichment workflows, reducing sample-to-sample variation from handling errors and $\mathrm{i}$ ill ncrease the speed of target verification.

The combination of these new analysis tools pushes combir atol al proteomics to new depths. With the advent of single cell proteomics and new updates on JOMn'tAQ it may even become possible to monitor proteolysis events in single cells [60]. $\mathrm{u}-\mathrm{tr}$ an inherent capacity of TMT tags and the TOMAHAQ targeted method to distinguish $r$ etu zen a carrier channel with over 500 cells and a single cell carrying a TMT tag this might enable analyzı. T the heterogeneity of post-translational modifications at the single cell level. This will allow us tr dra " a comprehensive map of cellular dynamics according to the size of a single cell, its protein c nnt ${ }^{n+}$, cell type, etc. The opportunities opened up by single cell proteomics can hardly be grasped. ju they will move the field even further towards clinical diagnostics. 


\section{Declaration of Conflict of Interests}

None.

\section{Acknowledgments}

Ulrich auf dem Keller acknowledges support by a Novo Nordisk Fou ndation Young Investigator Award [NNF16OC0020670]. Philipp Kastl is supported by a research fellowship from the German Research Foundation [project no. 415888450].

\section{References}

[1] Y. Liu, A. Beyer, R. Aebersold, On the Dependency of Cellular Protein Levels on mRNA Abundance, Cell. 165 (2016) 535-550. https://doi.org/https://doi.org/10.1016/j.cell.2016.03.014.

[2] L.M. Smith, N.L. Kelleher, T.C. for T.D. Proteomics, M. Linial, D. Goc Nlett, P. Langridge -Smith, Y. Ah Goo, G. Safford, L. Bonilla*, G. Kruppa, R. Zubarev, J. Rontr e, J. Chamot-Rooke, J. Garavelli, A.

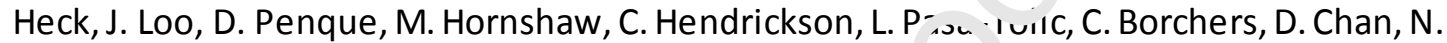
Young*, J. Agar, C. Masselon, M. Gross*, F. McLafferty, Y i vbi , Y. Ge, I. Sanders*, J. Langridge, J. Whitelegge*, A. Marshall, Proteoform: a single term de -cribing protein complexity, Nat. Methods. 10 (2013) 186. https://doi.org/10.1038/nnieth 2369.

[3] R. Aebersold, G.D. Bader, A.M. Edwards, J.E. van Ey'., M. .'ussmann, J. Qin, G.S. Omenn, The Biology/Disease-driven Human Proteome Proj $\mathrm{C}^{+}$([ /D-HPP): Enabling Protein Research for the Life Sciences Community, J. Proteome Res. 1 ' (2vis) 23-27. https://doi.org/10.1021/pr301151m.

[4] E.S. Witze, W.M. Old, K.A. Resing, N.G. Ah. Mapping protein post-translational modifications with mass spectrometry, Nat. Methc's. 4 (2007) 798-806. https://doi.org/10.1038/nmeth1100.

[5] A.F. Hühmer, R.G. Biringer, H. An.a o, A.N. Fonteh, M.G. Harrington, Protein analysis in human cerebrospinal fluid: Physiolog car - spects, current progress and future challenges, Dis. Markers. 22 (2006) 3-26. https://doi org,'10.1155/2006/158797.

[6] M. Wang, C.J. Herrmann, Nı. Simonovic, D. Szklarczyk, C. von Mering, Version 4.0 of PaxDb:

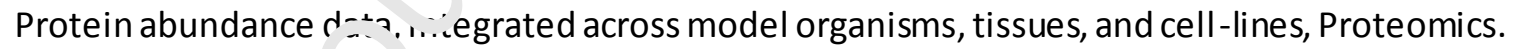
15 (2015) 3163-?16c ht ps://doi.org/10.1002/pmic.201400441.

[7] E. Boschetti, P.G. Rig etti, The ProteoMiner in the proteomic arena: A non-depleting tool for discovering low-abundance species, J. Proteomics. 71 (2008) 255-264. https://doi.org/https://doi.org/10.1016/j.jprot.2008.05.002.

[8] H.A.I. Yoshihara, S. Mahrus, J.A. Wells, Tags for labeling protein N-termini with subtiligase for proteomics, Bioorg. Med. Chem. Lett. 18 (2008) 6000-6003. https://doi.org/10.1016/j.bmcl.2008.08.044.

[9] K. Gevaert, M. Goethals, L. Martens, J. Van Damme, A. Staes, G. R. Thomas, J. Vandekerckhove, Exploring proteomes and analyzing protein processing by mass spectrometric identification of sorted N-terminal peptides, Nat. Biotechnol. 21(2003) 566-569. https://doi.org/10.1038/nbt810.

[10] A.S. Venne, F.A. Solari, F. Faden, T. Paretti, N. Dissmeyer, R.P. Zahedi, An improved workflow for quantitative $\mathrm{N}$-terminal charge-based fractional diagonal chromatography (ChaFRADIC) to study proteolytic events in Arabidopsis thaliana, Proteomics. 15(2015) 2458-2469. 
https://doi.org/10.1002/pmic.201500014.

[11] G. Shema, M.T.N. Nguyen, F.A. Solari, S. Loroch, A.S. Venne, L. Kollipara, A. Sickmann, S.H.L. Verhelst, R.P.Zahedi, Simple, scalable, and ultrasensitive tip-based identification of protease substrates, Mol. \&amp;Amp; Cell. Proteomics. 17 (2018) 826 LP - 834.

https://doi.org/10.1074/mcp.TIR117.000302.

[12] O. Kleifeld, A. Doucet, A. Prudova, U. auf dem Keller, M. Gioia, J.N. Kizhakkedathu, C.M. Overall, Identifying and quantifying proteolytic events and the natural $\mathrm{N}$ terminome by terminal amine isotopiclabeling of substrates, Nat. Protoc. 6(2011) 1578-1611.

https://doi.org/10.1038/nprot.2011.382.

[13] E. Madzharova, F. Sabino, U. auf dem Keller, Exploring Extracellular Matrix Degradomes by TMTTAILS N-Terminomics BT - Collagen: Methods and Protocols, in. ' Sagi, N.A. Afratis (Eds.), Springer New York, New York, NY, 2019: pp. 115-126. https://Nni.c. ./10.1007/978-1-4939-90955 8.

[14] V. Guryča, J. Lamerz, A. Ducret, P. Cutler, Qualitative impr ven ent and quantitative assessment of N-terminomics, Proteomics. 12 (2012) 1207-1216. hi. רs:// doi.org/10.1002/pmic.201100430.

[15] G.P.M. Mommen, B. van de Waterbeemd, H.D. Mei, ng, I i. Kersten, A.J.R. Heck, A.P.J.M. de Jong, Unbiased Selective Isolation of Protein $\mathrm{N}$-terminal $\mathrm{F}$ ept, ves from Complex Proteome Samples Using Phospho Tagging (PTAG) and TiO\&lt;sub $\times g^{+}$, , \& \&lt;/sub\&gt;-based Depletion, Mol.

\&amp;Amp; Cell. Proteomics. 11(2012) 832 .P - o'.2.

https://doi.org/10.1074/mcp.0112.018 $\angle 8=$

[16] G. Xu, S.B.Y.Shin, S.R. Jaffrey, Global pro ' 'ing of protease cleavage sites by chemoselective labeling of protein N-termini, Proc. । 'atl. Acad. Sci. 106 (2009) 19310 LP - 19315.

https://doi.org/10.1073/pnas.09r ఠ: ‘8ı 6.

[17] P.-H. Kuhn, K. Koroniak, S. Hos, , i Lulombo, U. Zeitschel, M. Willem, C. Volbracht, U. Schepers, A. Imhof, A. Hoffmeister, C. 'Ha.ss, S. Roßner, S. Bräse, S.F. Lichtenthaler, Secretome protein enrichment identifies ph:'sic 'ngical BACE1 protease substrates in neurons, EMBO J. 31 (2012) 3157-3168. https://dc: org, $10.1038 /$ emboj.2012.173.

[18] A. Serdaroglu, S A. I Müllt ", U. Schepers, S. Bräse, W. Weichert, S.F. Lichtenthaler, P. -H. Kuhn, An optimised version $\_{ }^{f}$ trie secretome protein enrichment with click sugars (SPECS) method leads to enhanced coverago,$f$ the secretome, Proteomics. 17 (2017) 1600423.

https://doi.org/10.1002/pmic.201600423.

[19] O. Schilling, P.F. Huesgen, O. Barré, C.M. Overall, Identification and Relati ve Quantification of Native and Proteolytically Generated Protein C-Termini from Complex Proteomes: C-Terminome Analysis BT - Network Biology: Methods and Applications, in: G. Cagney, A. Emili (Eds.), Humana Press, Totowa, NJ, 2011: pp. 59-69. https://doi.org/10.1007/978-1-61779-276-2_4.

[20] P. Van Damme, A. Staes, S. Bronsoms, K. Helsens, N. Colaert, E. Timmerman, F.X. Aviles, J. Vandekerckhove, K. Gevaert, Complementary positional proteomics for screening substrates of endo- and exoproteases, Nat. Methods. 7(2010) 512-515. https://doi.org/10.1038/nmeth.1469.

[21] K. Gevaert, J. Van Damme, M. Goethals, G.R. Thomas, B. Hoorelbeke, H. Demol, L. Martens, M. Puype, A. Staes, J. Vandekerckhove, Chromatographic Isolation of Methionine-containing Peptides for Gel-free Proteome Analysis, Mol. \&amp;Amp; Cell. Proteomics. 1(2002) 896 LP - 
903. https://doi.org/10.1074/mcp.M200061-MCP200.

[22] P. Schlage, T. Kockmann, F. Sabino, J.N. Kizhakkedathu, U. auf dem Keller, Matrix Metalloproteinase 10Degradomics in Keratinocytes and Epidermal Tissue Identifies Bioactive Substrates With Pleiotropic Functions, Mol. Cell. Proteomics . 14 (2015) 3234-3246. https://doi.org/10.1074/mcp.M115.053520.

[23] F. Sabino, O. Hermes, F.E. Egli, T. Kockmann, P. Schlage, P. Croizat, J.N. Kizhakkedathu, H. Smola, U. auf dem Keller, In Vivo Assessment of Protease Dynamics in Cutaneous Wound Healing by Degradomics Analysis of Porcine Wound Exudates, Mol. Cell. Proteomics . 14 (2015) 354-370. https://doi.org/10.1074/mcp.M114.043414.

[24] T. Klein, S.-Y. Fung, F. Renner, M.A. Blank, A. Dufour, S. Kang, M. Bolger-Munro, J.M. Scurll, J.J. Priatel, P. Schweigler, S. Melkko, M.R. Gold, R.I. Viner, C.H. Régr ¿r.r, S.E. Turvey, C.M. Overall, The paracaspase MALT1 cleaves HOIL1 reducing linear ubiquitination by ' UBAC to dampen Iymphocyte NF-kB signalling, Nat. Commun. 6 (2015) 8777.

https://doi.org/10.1038/ncomms9777.

[25] E.D. Crawford, J.E. Seaman, N. Agard, G.W. Hsu, O. Julie. S. Ivlahrus, H. Nguyen, K. Shimbo, H.A.I. Yoshihara, M. Zhuang, R.J. Chalkley, J.A. Wells, The [ egr. Base: A Database of Proteolysis in Healthy and Apoptotic Human Cells, Mol. \&amp;Amv, r-1l. Proteomics. 12 (2013) 813 LP - 824. https://doi.org/10.1074/mcp.0112.024372.

[26] N. Fortelny, S. Yang, P. Pavlidis, P.F. Lange, C M. ᄀ. erall, Proteome TopFIND 3.0 with TopFINDer and PathFINDer: database and analysic coc 's tu the association of protein terminito pre - and post-translational events, Nucleic Acia. R _s. 43 (2014) D290-D297.

https://doi.org/10.1093/nar/gku1n12.

[27] Y. Igarashi, A. Eroshkin, S. Gramat: אı 'a, K. Gramatikoff, Y. Zhang, J.W. Smith, A.L. Osterman, A. Godzik, CutDB: a proteolytic event da iabase, Nucleic Acids Res. 35 (2006) D546-D549. https://doi.org/10.1093/nar/, k/8+3.

[28] S. Kumar, B.J. van Raam, 7.S. Salvesen, P. Cieplak, Caspase Cleavage Sites in the Human Proteome: CaspDB, a D tabc ze of Predicted Substrates, PLoS One. 9(2014) e110539. https://doi.org/10.1 ; :-'juurnal.pone.0110539.

[29] N.D. Rawlings, A.J. ? $7 r$ rrett, P.D. Thomas, X. Huang, A. Bateman, R.D. Finn, The MERO PS database of proteolytic enz:'m 2 s, their substrates and inhibitors in 2017 and a comparison with peptidases in the PANTHER database, Nucleic Acids Res. (2018). https://doi.org/10.1093/nar/gkx1134.

[30] N. Fortelny, G.S. Butler, C.M. Overall, P. Pavlidis, Protease-inhibitor interaction predictions: Lessons on the complexity of protein-Protein interactions, Mol. Cell. Proteomics. (2017). https://doi.org/10.1074/mcp.M116.065706.

[31] S. Savickas, U. Auf Dem Keller, Targeted degradomics in protein terminomics and protease substrate discovery, Biol. Chem. (2017). https://doi.org/10.1515/hsz-2017-0187.

[32] H.A. Ebhardt, A. Root, C. Sander, R. Aebersold, Applications of targeted proteomics in systems biology and translational medicine, Proteomics. (2015).

https://doi.org/10.1002/pmic.201500004.

[33] M. Tachikawa, Y. Kaneko, S. Ohtsuki, Y. Uchida, M. Watanabe, H. Ohtsuka, T. Terasaki, Targeted proteomics-based quantitative protein atlas of pannexin and connexin subtypes in mouse and 
human tissues and cancer cell lines, J. Pharm. Sci. (2019). https://doi.org/10.1016/j.xphs.2019.09.024.

[34] T.A. Addona, S.E. Abbatiello, B. Schilling, S.J. Skates, D. R. Mani, D.M. Bunk, C.H. Spiegelman, L.J. Zimmerman, A.J.L. Ham, H. Keshishian, S.C. Hall, S. Allen, R.K. Blackman, C. H. Borchers, C. Buck, H.L. Cardasis, M.P. Cusack, N.G. Dodder, B.W. Gibson, J.M. Held, T. Hiltke, A. Jackson, E.B. Johansen, C.R. Kinsinger, J. Li, M. Mesri, T.A. Neubert, R.K. Niles, T.C. Pulsipher, D. Ransohoff, H. Rodriguez, P.A. Rudnick, D. Smith, D.L. Tabb, T.J. Tegeler, A.M. Variyath, L.J. Vega-Montoto, Å. Wahlander, S. Waldemarson, M. Wang, J.R. Whiteaker, L. Zhao, N.L. Anderson, S.J. Fisher, D.C. Liebler, A.G. Paulovich, F.E. Regnier, P. Tempst, S.A. Carr, Multi-site assessment of the precision and reproducibility of multiple reaction monitoring-based measurements of proteins in plasma, Nat. Biotechnol. (2009). https://doi.org/10.1038/nbt.1546.

[35] H.D. Cox, F. Lopes, G.A. Woldemariam, J.O. Becker, M.C. Parkin, , . Thomas, A.W. Butch, D.A. Cowan, M. Thevis, L.D. Bowers, A.N. Hoofnagle, Interlaborato' $y$ ar 'reement of insulin -like growth factor 1 concentrations measured by mass spectrometry, Clin. The m. (2014). https://doi.org/10.1373/clinchem.2013.208538.

[36] P. Giansanti, L. Tsiatsiani, T.Y. Low, A.J.R. Heck, Six altorna 'ive proteases for mass spectrometrybased proteomics beyond trypsin, Nat. Protoc. (201‘. hti os://doi.org/10.1038/nprot.2016.057.

[37] A.D. Catherman, O.S. Skinner, N.L. Kelleher, Ton nown pruteomics: Facts and perspectives, Biochem. Biophys. Res. Commun. 445 (2014) $6:-613$.

https://doi.org/https://doi.org/10.1016/i bi c.2U14.02.041.

[38] S.L. King, C.K. Goth, U. Eckhard, H.J. Jos.'-i A.D. Haue, S.Y. Vakhrushev, K.T. Schjoldager, C.M. Overall, H.H. Wandall, TAILS N-terminomic. and proteomics reveal complex regulation of proteolytic cleavage by O-glycosylatı ?. J. Biol. Chem. (2018).

https://doi.org/10.1074/jbc.RA1 $8 \varkappa^{1978 . ~}$

[39] D.B. Trentini, M.J. Suskiewic: A. T. suck, R. Kurzbauer, L. Deszcz, K. Mechtler, T. Clausen, Arginine phosphorylation marks prc eins for degradation by a Clp protease, Nature. (2016). https://doi.org/10.1038/r, tur 220122 .

[40] J.W.H. Wong, G. Cag it; Aı overview of label-free quantitation methods in proteomics by mass spectrometry., iv'stı. dds Mol. Biol. (2010). https://doi.org/10.1007/978-1-60761-444-9_18.

[41] A. Bourmaud, S. Gㄱl: an, B. Domon, Parallel reaction monitoring using quadrupole-Orbitrap mass spectrometer: Principle and applications, Proteomics. (2016).

https://doi.org/10.1002/pmic.201500543.

[42] B. MacLean, D.M. Tomazela, N. Shulman, M. Chambers, G. L. Finney, B. Frewen, R. Kern, D.L. Tabb, D.C. Liebler, M.J. MacCoss, Skyline: An open source document editor for creating and analyzing targeted proteomics experiments, Bioinformatics. (2010).

https://doi.org/10.1093/bioinformatics/btq054.

[43] M. Choi, C.Y. Chang, T. Clough, D. Broudy, T. Killeen, B. MacLean, O. Vitek, MSstats: An R package for statistical analysis of quantitative mass spectrometry-based proteomic experiments, Bioinformatics. (2014). https://doi.org/10.1093/bioinformatics/btu305.

[44] C. Galitzine, J.D. Egertson, S. Abbatiello, C.M. Henderson, L.K. Pino, M. MacCoss, A.N. Hoofnagle, $\mathrm{O}$. Vitek, Nonlinear regression improves accuracy of characterization of multiplexed mass 
spectrometric assays, Mol. Cell. Proteomics. (2018). https://doi.org/10.1074/mcp.RA117.000322.

[45] S.M. Henry, E. Sutlief, O. Salas-Solano, J. Valliere-Douglass, ELISA reagent coverage evaluation by affinity purification tandem mass spectrometry, MAbs. (2017). https://doi.org/10.1080/19420862.2017.1349586.

[46] U. Auf Dem Keller, A. Prudova, U. Eckhard, B. Fingleton, C. M. Overall, Systems-level analysis of proteolytic events in increased vascular permeability and complement activation in skin inflammation, Sci. Signal. (2013). https://doi.org/10.1126/scisignal.2003512.

[47] U. Eckhard, P.F. Huesgen, O. Schilling, C.L. Bellac, G.S. Butler, J.H. Cox, A. Dufour, V. Goebeler, R. Kappelhoff, U. auf dem Keller, T. Klein, P.F. Lange, G. Marino, C.J. Morrison, A. Prudova, D. Rodriguez, A.E. Starr, Y. Wang, C.M. Overall, Active site specificity profiling of the matrix metalloproteinase family: Proteomic identification of 4300 clear ' je sites by nine MMPs explored with structural and synthetic peptide cleavage analyses, Matrix Rioı. 19 (2016) 37-60. https://doi.org/https://doi.org/10.1016/j.matbio.2015.09.003

[48] N. Fortelny, J.H. Cox, R. Kappelhoff, A.E. Starr, P.F. Lange.I Pai lidis, C.M. Overall, Network Analyses Reveal Pervasive Functional Regulation Betwe $\eta$ Proteases in the Hum an Protease Web, PLOS Biol. 12 (2014) e1001869. https://doi.org/10.1'/1,; ournal. pbio.1001869.

[49] T. Klein, U. Eckhard, A. Dufour, N. Solis, C.M. Overal', Pru+eolytic Cleavage - Mechanisms, Function, and "omic" Approaches for a Near-L' Jir, u itous Posttranslational Modification, Chem. Rev. (2018). https://doi.org/10.1021/acs.chcmı “./b00120.

[50] M. Grozdanić, R. Vidmar, M. Vizoviše! M. onović, Degradomics in Biomarker Discovery, PROTEOMICS - Clin. Appl. (2019). https:/'Toi.org/10.1002/prca.201800138.

[51] S.S.H. Weng, F. Demir, E.K. Ergin, S DI1 - berger, A. Uzozie, D. Tuscher, L. Nierves, J. Tsui, P.F. Huesgen, P.F. Lange, Sensitive d $t \in \mathrm{r} n$ in nation of proteolytic proteoforms in limited microscale proteome samples, Mol. Cell. rr teumics. (2019). https://doi.org/10.1074/mcp.tir119.001560.

[52] R. Bruderer, O.M. Bernharc T. Landhi, Y. Xuan, J. Sondermann, M. Schmidt, D. Gomez-Varela, L. Reiter, Optimization of exp rrirnental parameters in data-independent mass spectrometry significantly increasec $d t{ }_{1}{ }^{+t}$. and reprodu cibility of results, Mol. Cell. Proteomics. (2017). https://doi.org/10.: 074/ ncp.RA117.000314.

[53] S. Gessulat, T. Schmı 't, D.P.Zolg, P. Samaras, K. Schnatbaum, J. Zerweck, T. Knaute, J. Rechenberger, B. Lelanghe, A. Huhmer, U. Reimer, H.C. Ehrlich, S. Aiche, B. Kuster, M. Wilhelm, Prosit: proteome-wide prediction of peptide tandem mass spectra by deep learning, Nat. Methods. (2019). https://doi.org/10.1038/s41592-019-0426-7.

[54] R. Bąchor, M. Waliczek, P. Stefanowicz, Z. Szewczuk, Trends in the Design of New Isobaric Labeling Reagents for Quantitative Proteomics, Mol. . 24 (2019).

https://doi.org/10.3390/molecules24040701.

[55] T.S. Batth, J. V Olsen, Offline high $\mathrm{pH}$ reversed-phase peptide fractionation for deep phosphoproteome coverage, in: Methods Mol. Biol., 2016. https://doi.org/10.1007/978-1-49393049-4_12.

[56] L. Chen, Y. Shan, Y. Weng, Z. Sui, X. Zhang, Z. Liang, L. Zhang, Y. Zhang, Hydrophobic TaggingAssisted N-Termini Enrichment for In-Depth N-Terminome Analysis, Anal. Chem. 88 (2016) 83908395. https://doi.org/10.1021/acs.analchem.6b02453. 
[57] B.K. Erickson, C.M. Rose, C.R. Braun, A.R. Erickson, J. Knott, G.C. McAlister, M. Wühr, J.A. Paulo, R.A. Everley, S.P. Gygi, A Strategy to Combine Sample Multiplexing with Targeted Proteomics Assays for High-Throughput Protein Signature Characterization, Mol. Cell. (2017). https://doi.org/10.1016/j.molcel.2016.12.005.

[58] C.M. Rose, B.K. Erickson, D.K. Schweppe, R. Viner, J. Choi, J. Rogers, R. Bomgarden, S.P. Gygi, D.S. Kirkpatrick, TomahaqCompanion: A Tool for the Creation and Analysis of Isobaric Label Based Multiplexed Targeted Assays, J. Proteome Res. (2019). https://doi.org/10.1021/acs.jproteome.8b00767.

[59] X. Zhong, Q. Yu, F. Ma, D.C. Frost, L. Lu, Z. Chen, H. Zetterberg, C. Carlsson, O. Okonkwo, L. Li, HOTMAQ: A Multiplexed Absolute Quantification Method for Targeted Proteomics, Anal. Chem. (2019). https://doi.org/10.1021/acs.analchem.8b04580.

[60] B. Budnik, E. Levy, G. Harmange, N. Slavov, SCoPE-MS: mass spartru netry of single mammalian cells quantifies proteome heterogeneity during cell differentic tion Genome Biol. (2018). https://doi.org/10.1186/s13059-018-1547-5. 
Table S1: Publication number and corresponding pubmedID as referred to from table 1 a nd figure 1.

\begin{tabular}{|c|c|c|}
\hline TAILS & & PMID \\
\hline & 1 & 31629960 \\
\hline & 2 & 31463921 \\
\hline & 3 & 31601107 \\
\hline & 4 & 31337208 \\
\hline & 5 & 31462935 \\
\hline & 6 & 31393699 \\
\hline & 7 & 31606086 \\
\hline & 8 & 30926607 \\
\hline & 9 & 30705123 \\
\hline & 10 & 30267877 \\
\hline & 11 & 30840238 \\
\hline & 12 & 30257879 \\
\hline & 13 & 30371095 \\
\hline & 14 & 30284925 \\
\hline & 15 & 30377279 \\
\hline & 16 & 29593093 \\
\hline & 17 & 29437971 \\
\hline & 18 & 29358340 \\
\hline & 19 & 29035686 \\
\hline & 20 & 29318539 \\
\hline & 21 & 28730820 \\
\hline & 22 & 28082348 \\
\hline & 23 & 28315245 \\
\hline & 24 & 28299737 \\
\hline & 25 & 28109429 \\
\hline & 26 & 274772 \\
\hline & 27 & 270894 \\
\hline & 28 & $2674 C^{?}$ \\
\hline & 29 & 26587561 \\
\hline & 30 & 26475864 \\
\hline & 31 & 26371235 \\
\hline & 32 & 26061547 \\
\hline & 33 & 26258467 \\
\hline & 34 & 25871442 \\
\hline & 35 & 25516628 \\
\hline & 36 & 25331112 \\
\hline & 37 & 25310974 \\
\hline & 38 & 23811845 \\
\hline & 39 & 24281761 \\
\hline
\end{tabular}

\begin{tabular}{|c|c|c|}
\hline & 40 & 23519473 \\
\hline & 41 & 22940918 \\
\hline & 42 & 23667905 \\
\hline & 43 & 22367194 \\
\hline & 44 & 22577022 \\
\hline & 45 & 21972973 \\
\hline & 46 & 21959240 \\
\hline & 47 & 21693781 \\
\hline & 48 & 21646356 \\
\hline & 49 & 21604129 \\
\hline COFRADIC & & PMID \\
\hline & 50 & 29358340 \\
\hline & 51 & $2831574^{7}$ \\
\hline & 52 & $28315<13$ \\
\hline & 53 & $263 \overline{933} \overline{18}$ \\
\hline & 54 & $2 F 15,-\overline{30}$ \\
\hline & 55 & 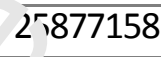 \\
\hline & $i \overline{6}$ & $\angle 5381060$ \\
\hline & 57 & 25383893 \\
\hline & 58 & 24816145 \\
\hline & 59 & 24536027 \\
\hline & 60 & 24505135 \\
\hline- & 61 & 24974297 \\
\hline & 62 & 24567107 \\
\hline & 63 & 23620545 \\
\hline & 64 & 23705892 \\
\hline & 65 & 23429522 \\
\hline & 66 & 22825847 \\
\hline & 67 & 22559236 \\
\hline & 68 & 22313033 \\
\hline & 69 & 22065552 \\
\hline & 70 & 21790200 \\
\hline & 71 & 21619078 \\
\hline & 72 & 21799483 \\
\hline & 73 & 21750686 \\
\hline & 74 & 21953040 \\
\hline & 75 & 21070068 \\
\hline & 76 & 19911852 \\
\hline & 77 & 19660099 \\
\hline & 78 & 19420222 \\
\hline
\end{tabular}

\begin{tabular}{|c|c|c|}
\hline & 79 & 19065607 \\
\hline & 80 & 19544022 \\
\hline & 81 & 18402783 \\
\hline & 82 & 18318009 \\
\hline & 83 & 18021241 \\
\hline & 84 & 17918875 \\
\hline & 85 & 17444671 \\
\hline & 86 & 17461103 \\
\hline & 87 & 17266347 \\
\hline & 88 & 17891751 \\
\hline 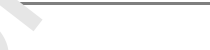 & 89 & 16179924 \\
\hline & 90 & 16038019 \\
\hline & 91 & 12665801 \\
\hline SPECS & & PMID \\
\hline & 92 & 29716987 \\
\hline & 93 & 27991726 \\
\hline & 94 & 25827571 \\
\hline & 95 & 22728825 \\
\hline PROTOMAP & & PMID \\
\hline & 96 & 28315249 \\
\hline & 97 & 27708557 \\
\hline & 98 & 27451424 \\
\hline & 99 & 27378148 \\
\hline & 100 & 24967658 \\
\hline & 101 & 22623320 \\
\hline & 102 & 20943600 \\
\hline & 103 & 21584940 \\
\hline & 104 & 18724940 \\
\hline TMPP & & PMID \\
\hline & 105 & 26481993 \\
\hline & 106 & 22749915 \\
\hline & 107 & 22695497 \\
\hline & 108 & 18955433 \\
\hline & 109 & 23641718 \\
\hline & 110 & 25769014 \\
\hline ATOMS & & PMID \\
\hline & 111 & 31324718 \\
\hline & 112 & 29946113 \\
\hline & 113 & 20876890 \\
\hline & 114 & 22078539 \\
\hline
\end{tabular}




\begin{tabular}{|c|c|c|}
\hline C-Terminom & ics & PMID \\
\hline & 115 & 20526347 \\
\hline & 116 & 31634432 \\
\hline & 117 & 31195796 \\
\hline & 118 & 27071760 \\
\hline & 119 & 26361894 \\
\hline & 120 & 21877277 \\
\hline & 121 & 26356223 \\
\hline & 122 & 21812462 \\
\hline & 123 & 27363206 \\
\hline & 124 & 28315248 \\
\hline PTAG & & PMID \\
\hline & 125 & 22729381 \\
\hline Biotinylation & & PMID \\
\hline & 126 & 16299481 \\
\hline & 127 & 17650073 \\
\hline & 128 & 21604127 \\
\hline & 129 & 18722006 \\
\hline & 130 & 24974296 \\
\hline & 131 & 29155430 \\
\hline & 132 & 19767749 \\
\hline NEDDylator & & PMID \\
\hline & 133 & 23201124 \\
\hline Yeast-2-Hybr & & PMID \\
\hline & 134 & 29362422 \\
\hline & 135 & 27471094 \\
\hline & 136 & 22898924 \\
\hline & 137 & J205469r \\
\hline & 138 & $162 \perp 56$ \\
\hline & 139 & 1531596 \\
\hline HUNTER & & PMID \\
\hline & 140 & 31471496 \\
\hline CheFRADIC & & PMID \\
\hline & 141 & 26010716 \\
\hline & 142 & 27535140 \\
\hline
\end{tabular}




\section{CRediT author} statement

Simonas Savickas: Writing Original Draft Philipp Kastl: Writing - Original Draft

Ulrich auf dem Keller: Writing - Review \& Editing 


\section{Declaration of interests}

$\bigotimes$ The authors declare that

they have no known

competing financial interests

or personal relationships that

could have appeared to

influence the work reported

in this paper.

$\square$ The authors declare the

following financial

interests/personal

relationships which may be

considered as potential

competing interests: 
Highlights

- Whole

proteome mass

spectrometry

fails to detect

low-abundant

proteolytic

peptides

- Degradomics

techniques

enrich and

detect low-

abundant

proteoforms

- Global discovery degradomics

allows for

protease-

generated

biomarker

identification

- Highly sensiti'e

targeted

degradomics

validates

identified

candidates

- Combinatorial

degradomics

further evolves

MS towards

clinical

application 